\title{
Contraception coverage and methods used among women in South Africa: A national household survey
}

\author{
M F Chersich, ${ }^{1} \mathrm{MB}$ BCh, PhD; N Wabiri, ${ }^{2} \mathrm{MSc}, \mathrm{MBA}, \mathrm{PhD} ; \mathbf{K}$ Risher, ${ }^{3} \mathrm{MHS}$; O Shisana, ${ }^{4} \mathrm{MA}, \mathrm{ScD} ;$ D Celentano, ${ }^{3} \mathrm{MHS}, \mathrm{ScD}$; \\ T Rehle, ${ }^{2,5} \mathrm{MD}$, PhD; M Evans, ${ }^{6}$ MA; H Rees, ${ }^{1,7}$ MB BChir, MA, MRCGP \\ ${ }^{1}$ Wits Reproductive Health and HIV Institute, Faculty of Health Sciences, University of the Witwatersrand, Johannesburg, South Africa \\ ${ }^{2}$ Human Sciences Research Council, Cape Town, South Africa \\ ${ }^{3}$ Department of Epidemiology, Johns Hopkins Bloomberg School of Public Health, Baltimore, MD, USA \\ ${ }^{4}$ Evidenced Based Solutions, Cape Town; and Department of Psychiatry and Mental Health, Faculty of Health Sciences, University of Cape Town, \\ South Africa \\ ${ }^{5}$ Centre for Infectious Disease Epidemiology and Research, School of Public Health and Family Medicine, University of Cape Town, South Africa, \\ ${ }^{6}$ Department of Anthropology, Faculty of Graduate Studies, York University, Toronto, Canada \\ ${ }^{7}$ London School of Hygiene and Tropical Medicine, University of London, UK
}

Corresponding author: M F Chersich (mchersich@wrhi.ac.za)

Background. Globally, family planning services are being strengthened and the range of contraceptive choices expanded. Data on contraceptive coverage and service gaps could help to shape these initiatives.

Objective. To assess contraception coverage in South Africa (SA) and identify underserved populations and aspects of programming that require strengthening.

Methods. Data from a 2012 SA household survey assessed contraception coverage among 6296 women aged 15 - 49 years and identified underserved populations.

Results. Two-thirds had an unintended pregnancy in the past 5 years, a quarter of which were contraceptive failures. Most knew of injectable (92.0\%) and oral contraception (89.9\%), but fewer of intrauterine devices (56.1\%) and emergency contraception (47.3\%). Contraceptive prevalence was $49.1 \%$, and $41.8 \%$ women used modern non-barrier methods. About half had ever used injectable contraception. Contraception was lower in black Africans and younger women, who used a limited range of methods.

Conclusion. Contraception coverage is higher than many previous estimates. Rates of unintended pregnancy, contraceptive failure and knowledge gaps, however, demonstrate high levels of unmet need, especially among black Africans and young women.

S Afr Med J 2017;107(4):307-314. DOI:10.7196/SAMJ.2017.v107i4.12141

Contraception has profound benefits for women and society, including reduced maternal and infant mortality and morbidity, empowerment of women to make informed choices about fertility, economic advancement, and a reduction in the number of children infected with HIV. ${ }^{[1,2]}$ In recent decades, contraceptive use has risen markedly worldwide, although at a much slower pace in sub-Saharan Africa than elsewhere. ${ }^{[3]}$ About a quarter of women in sub-Saharan Africa currently use modern contraceptive methods, with levels highest in southern Africa. ${ }^{[4,5]}$ In South Africa (SA), for example, estimates of the proportion of women of reproductive age who are protected against unplanned pregnancies, using modern contraceptive methods, have increased steadily from $26.3 \%$ in $2002 / 2003$ to $37.3 \%$ in $2013 / 2014$. $^{[6]}$ These figures are drawn from a district health information system covering the public sector, while population level end-user data have yielded somewhat different estimates. For example, the 2003 Demographic and Health Survey, ${ }^{[7]}$ the most recent available national report, found a contraceptive prevalence of $64.7 \%$, similar to more recent modelling estimates. ${ }^{[8]}$ Regardless of which figures are correct, the continued rise in the number of terminations of pregnancy in SA among all age groups suggests that substantial deficiencies remain in accessing family planning services. ${ }^{[6]}$

Increasing the range of contraception choices available is a key component of ensuring access for women, their partners and couples to the most effective method they wish to use. Global policymakers and policy advocates have placed particular emphasis on increasing access to long-acting reversible contraception (LARC) methods, including intrauterine devices and subdermal implants. These are highly effective, and markedly diminish the need for user adherence and contact with health workers. Many providers in SA are, however, still unfamiliar with these methods. ${ }^{[9-11]}$ In SA, as throughout subSaharan Africa, the injectable progestins depot-medroxyprogesterone acetate (DMPA) and norethisterone enanthate (NET-EN) are the most popular contraceptive methods, ${ }^{[4]}$ and their use has continued to rise over time. ${ }^{[12]}$ Nationally, about 5.8 million doses of DMPA are administered annually. ${ }^{[6]}$ By contrast, in most high-income countries, use of injectable contraceptives is rare, aside from in marginalised groups, such as poor, African American or aboriginal women. ${ }^{[13-16]}$ The popularity of injectables in sub-Saharan Africa is ascribed to its convenience for providers and women, cost effectiveness, and high acceptability among women and health providers. ${ }^{[2]}$ Method discontinuation and contraceptive failure, however, frequently occur with this method. ${ }^{[17,18]}$

Using data from the 2012 SA National HIV Prevalence, Incidence and Behaviour Survey, ${ }^{[19]}$ this analysis assesses the extent of unmet contraceptive need, and estimates the overall contraception coverage and methods used. We also aimed to identify underserved populations through examining the demographic factors and sexual behaviours 
associated with contraceptive use. In addition to providing updated figures on key family planning indicators, the study seeks to identify the areas that need to be addressed to strengthen family planning services in SA and similar settings.

\section{Methods \\ Survey sampling, field and laboratory procedures}

The fourth SA National HIV Prevalence, Incidence and Behaviour Survey ${ }^{[19]}$ took place from January to November 2012. This population-based survey applied multistage stratified sampling by province; locality (urban formal, urban informal, rural formal including commercial farms, and rural informal or tribal authority areas); and predominant racial groups. Sampling frames were based on enumerator areas (EA) used in the national census, updated in 2007 to reflect changes in the sociodemographic profile of the country since 2001. In total, $1000 \mathrm{EAs}$ were selected from a database of $86000 \mathrm{EAs}$ as the primary sampling units, 15 households within each EA constituted the secondary sampling unit (15 000 households), and all persons in the selected households were eligible for the survey. Additional details of the survey methodology, including fieldwork procedures and quality control measures, are described elsewhere. ${ }^{[19]}$

Dried blood spot specimens collected by finger prick were tested in a laboratory for HIV antibodies using a testing algorithm with three different immunoassays. All HIV testing was anonymous and unlinked to personal identifiers. Individuals were given an opportunity to access their HIV test results 8 weeks after testing at designated facilities, using bar codes to preserve anonymity. The study protocol was approved by the Human Sciences Research Council's Research Ethics Committee (ref. no. 5/17/11/10) and the Human Subjects Review from the Centers for Disease Control and Prevention's Global AIDS Programme. Only women in the reproductive age group (15 - 49 years) who had ever had sex were included in this analysis.

\section{Study measures}

Data were drawn from face-to-face questionnaires, which elicited detailed information on demographic and socioeconomic characteristics, contraception use, sexual behaviours and other risk factors for HIV infection. In a multiple-response question, women were asked if they ever had used or were currently using a contraceptive method, specifically injectable or oral contraception, an intrauterine device (IUD), female or male sterilisation, or natural family planning. In a separate question, women reported condom use at last sex and consistent condom use with their last partner. Injectable contraception referred to the use of either DMPA or NET-EN, as women were not asked to differentiate between these methods.

Contraceptive prevalence was defined as the percentage of women aged 15 - 49 years, who were using (or whose partner was using) a contraceptive method at the time of the interview. ${ }^{[20]}$ Contraceptive methods consisted of injectable and oral hormones, IUDs, female and male sterilisation, emergency contraception, and other (consistent condom use with last partner, natural family planning, or withdrawal). The indicator only includes women who were sexually active (had sex in previous 12 months), and not pregnant or amenorrhoeic. Injectable and oral hormones, IUDs, and female or male sterilisation were considered modern contraception. Condoms were excluded from this definition as biases inherent in its measurement may both under- and overestimate its use for contraception, hampering interpretation. ${ }^{[21]}$ We used unintended pregnancy as a proxy indicator of unmet need for contraception.

Socioeconomic quartiles were derived from measures of household living standards captured in the household questionnaire: infrastructure and housing characteristics (source of drinking water, access to electricity, main source of energy for cooking and type of toilet used) and household ownership of durable assets (presence of a working refrigerator, radio, television, cellphone and landline phone). Details of how quartiles were generated and the rationale for using quartiles, rather than the commonly used quintiles, are provided elsewhere. ${ }^{[22,23]}$

\section{Data management and analysis}

After double data entry, data validity was verified using the Census and Survey Processing System (CSPro) (US Census Bureau, USA). ${ }^{[24]}$ Data were analysed using Stata version 14.0 (Stata Corporation, USA), taking into account the complex multilevel sampling design (by age, race group and province) and participant non-response. Summary indices for descriptive analysis are weighted percentages, and unweighted counts are provided.

Descriptive analyses were conducted to investigate whether use of any contraception or individual method was associated with demographic, social or economic characteristics, or pregnancy history. We also determined whether sexual behaviour, condom use, HIV risk perception and HIV status varied between women using different contraceptive methods. In descriptive and bivariate analyses, associations were identified using the Rao-Scott F statistic to determine $p$-values.

\section{Results}

\section{Unmet need for contraception}

Among the 8482 women aged 15 - 49 years who had ever had sex, $81.1 \%$ reported being sexually active in the past year (Table 1 ). These figures were lowest among women 35 - 49 years (75.1\%) compared with $83.0 \%$ in those $15-19$ years, and about $85 \%$ among the other age groups $(p<0.001)$. Age was also associated with unintended pregnancy among the 3538 women who reported a pregnancy in the past 5 years. Overall, a third of these women (33.5\%) had desired to become pregnant at the time of their last pregnancy; this was reported by only $10.1 \%$ of women $15-19$ years of age and $20.9 \%$ of those $20-24$ years of age $(p<0.001)$. At the time of the pregnancy, about half of women 15 - 19 years (51.2\%) and 20 - 24 years (48.5\%) had not wanted to have a child. In older women, these levels were $41.3 \%$ for women 25 - 34 years and $44.9 \%$ for those 35 - 49 years. Among the 276 women who were pregnant at the time of the survey, only half $(50.6 \%)$ had wanted to become pregnant. About a quarter $(24.0 \%)$ of all women who reported a pregnancy in the past 5 years had been using a contraceptive method at the time of their pregnancy. These levels were only $12.8 \%$ in 15 - 19-year-olds compared with $19.7 \%$ in 20 - 24 -year olds and $26.1 \%$ in women $\geq 25$ years $(p<0.01)$.

\section{Contraceptive knowledge and prevalence}

Of women who had ever had sex, almost all (92.0\%) were aware of injectable contraception, with similarly high levels of knowledge of oral contraception (89.9\%) and female sterilisation (73.3\%; Table 2). Only about half, however, had heard of IUDs, emergency contraception or male sterilisation $(56.1 \%, 47.3 \%$, and $45.3 \%$, respectively). Levels of knowledge among women aged 15 - 19 years were lower than those of older women for each contraceptive method. Most notably, only $30.9 \%$ of 15 - 19 -year-olds knew of IUDs and $36.2 \%$ of emergency contraception, considerably lower than for other women. On average, women had heard of 4 - 5 contraceptive methods in total. Just under half of the 8245 women responding to questions about lifetime contraception use (women who had ever had sex) reported having ever used injectable contraception (46.2\%) and a quarter had ever used oral contraception $(25.6 \%)$. Aside from the 'other contra- 
Table 1. Indices of unmet need for contraception in different age groups, SA, 2012

\begin{tabular}{|c|c|c|}
\hline Variable & Prevalence & $p$-value \\
\hline \multicolumn{3}{|c|}{$\begin{array}{l}\text { Sexually active past } 6 \text { months, } \\
\text { age (years)* }\end{array}$} \\
\hline $15-19(n=659)$ & 83.0 & \\
\hline $20-24(n=1489)$ & 84.6 & \\
\hline $25-34(n=2772)$ & 85.7 & \\
\hline $35-49(n=3576)$ & 75.1 & $<0.001$ \\
\hline \multicolumn{3}{|c|}{ Currently pregnant, age (years) ${ }^{\dagger}$} \\
\hline $15-19(n=500)$ & 6.6 & \\
\hline $20-24(n=1 \quad 197)$ & 6.1 & \\
\hline $25-34(n=2235)$ & 8.1 & \\
\hline $35-49(n=2587)$ & 1.7 & $<0.001$ \\
\hline \multicolumn{3}{|c|}{$\begin{array}{l}\text { Intended to become pregnant, } \\
\text { age (years) }{ }^{\ddagger}\end{array}$} \\
\hline $15-19(n=216)$ & 10.1 & \\
\hline $20-24(n=805)$ & 20.9 & \\
\hline $25-34(n=1613)$ & 37.4 & \\
\hline $35-49(n=904)$ & 42.1 & $<0.001$ \\
\hline \multicolumn{3}{|c|}{$\begin{array}{l}\text { Did not want to have a child, } \\
\text { age (years) }\end{array}$} \\
\hline $15-19(n=216)$ & 51.2 & \\
\hline $20-24(n=805)$ & 48.5 & \\
\hline $25-34(n=1613)$ & 41.3 & \\
\hline $35-49(n=904)$ & 44.9 & $<0.001$ \\
\hline \multicolumn{3}{|c|}{$\begin{array}{l}\text { Used contraception at time of } \\
\text { pregnancy, age (years) }\end{array}$} \\
\hline $15-19(n=214)$ & 12.8 & \\
\hline $20-24(n=800)$ & 19.7 & \\
\hline $25-34(n=1610)$ & 26.1 & \\
\hline $35-49(n=906)$ & 26.1 & $<0.01$ \\
\hline \multicolumn{3}{|c|}{$\begin{array}{l}\text { Among women who had ever had sex ( } n=8482) \text {. } \\
\text { "Among sexually active women. } \\
\text { "Among women who were pregnant in past } 5 \text { years. }\end{array}$} \\
\hline
\end{tabular}

ceptive' category, ever use of all other methods (IUD, female sterilisation, male sterilisation, and emergency contraception) was $<10 \%$. Overall, current contraceptive prevalence was $49.1 \%$, and $41.8 \%$ of women were using modern, non-barrier methods (Table 3). Injectable contraception was by far the most common method, used by $25.0 \%$ of women. Other methods were several-fold less common and only a negligible portion were using an IUD (1.6\%). Among injectable contraception users, the majority had obtained this method of contraception at a clinic or community health centre (70.8\%), while other methods were much less likely to have been provided at these facilities ( $<50 \%$ for all). A notably higher proportion of oral and emergency contraception users, and female and male sterilisation users, acquired their contraception from a private facility or doctor (23.0\%, $21.3 \%, 26.5 \%$ and $41.5 \%$ respectively), while a considerable proportion of IUDs were obtained from a pharmacy (27.3\%).

\section{Sociodemographic factors and contraception use}

Table 3 shows the distribution of contraceptive methods among the 6296 sexually active women, stratified by sociodemographic groups. Only about a third of women aged 15 - 19 years were using modern contraception, only $5.0 \%$ were using oral contraception, and $0.4 \%$ an IUD. Compared with their younger counterparts, more women aged 20 - 34 or 35 - 49 years were using modern contraception $(42.7 \%$ and $41.8 \%$, respectively). A considerable proportion of women 35 - 49 years old had been sterilised (16.4\%), but their use of injectables (16.2\%) was much lower than that of women aged $15-19$ years $(26.1 \%)$ and those 20 - 34 years $(30.5 \%)$.

Contraceptive coverage was highest in the Western Cape (54.0\%), Eastern Cape (50.7\%) and KwaZulu-Natal (50.1\%), and lowest in the Northern Cape (42.2\%) and Mpumalanga (45.0\%). Prevalence of any contraceptive use differed by race, ranging from $47.2 \%$ in black Africans, $52.4 \%$ in coloureds, $61.1 \%$ in Indians/Asians, to $61.9 \%$ in whites $(p<0.001)$. While $27.5 \%$ of black African and $23.8 \%$ of coloured women were using injectables, the method is only used by $6.8 \%$ of Indians/Asians, and $4.8 \%$ of whites $(p<0.001)$. Oral contraception, on the other hand, was more likely to be reported by white and Indian/Asian women (22.8\% and $22.5 \%$, respectively). IUDs were also relatively more common among whites (6.0\%) and Indians/Asians (3.8\%). Female sterilisation among Indian/Asian

Table 2. Contraceptive method awareness, prevalence and access point of SA women, 2012

\begin{tabular}{|c|c|c|c|c|c|c|c|}
\hline Variable (unweighted $n$ ) & $\begin{array}{l}\text { Injectable con- } \\
\text { traception, \% }\end{array}$ & $\begin{array}{l}\text { Oral con- } \\
\text { traception, \% }\end{array}$ & IUD, \% & $\begin{array}{l}\text { Female } \\
\text { sterilisation, \% }\end{array}$ & $\begin{array}{l}\text { Male } \\
\text { sterilisation, \% }\end{array}$ & $\begin{array}{l}\text { Emergency con- } \\
\text { traception, \% }\end{array}$ & $\begin{array}{l}\text { Other, } \\
\%^{\dagger}\end{array}$ \\
\hline Knows of method ( $n=8507)$ & 92.0 & 89.9 & 56.1 & 73.3 & 45.3 & 47.3 & 61.8 \\
\hline Ever used method ( $n=8245)$ & 46.2 & 25.6 & 4.5 & 8.2 & 1.9 & 5.7 & 18.7 \\
\hline Currently used method $(n=6296)^{*}$ & 25.0 & 8.6 & 1.6 & 8.1 & 2.3 & 0.8 & 11.4 \\
\hline \multicolumn{8}{|l|}{ Where obtained method } \\
\hline Hospital $(n=567)$ & 10.2 & 8.3 & 8.4 & 34.8 & 25.6 & 19.7 & 9.1 \\
\hline Clinic or CHC $(n=1935)$ & 70.8 & 42.3 & 48.5 & 24.0 & 19.9 & 40.6 & 48.9 \\
\hline Mobile clinic $(n=124)$ & 3.5 & 1.9 & 1.5 & 1.0 & 0.1 & 7.3 & 0.8 \\
\hline Family planning clinic $(n=345)$ & 8.3 & 10.9 & 3.6 & 4.5 & 1.2 & 1.5 & 4.3 \\
\hline Private facility $(n=177)$ & 1.1 & 1.0 & 2.9 & 23.5 & 38.7 & 0.0 & 2.1 \\
\hline Private doctor $(n=283)$ & 1.9 & 22.0 & 5.3 & 3.0 & 2.8 & 21.3 & 14.0 \\
\hline Pharmacy $(n=179)$ & 2.3 & 10.7 & 27.3 & 2.6 & 6.6 & 0.5 & 3.6 \\
\hline Other $(n=332)$ & 1.8 & 2.7 & 2.4 & 6.7 & 5.0 & 9.2 & 17.2 \\
\hline
\end{tabular}


Table 3. Demographic characteristics of current contraceptive users among sexually active women, SA, 2012

\begin{tabular}{|c|c|c|c|c|c|c|c|c|c|c|}
\hline $\begin{array}{l}\text { Variable } \\
\text { (unweighted } n \text { ) }\end{array}$ & $\begin{array}{l}\text { Any } \\
\text { method, \% }\end{array}$ & $\begin{array}{l}\text { Modern } \\
\text { method, \% }{ }^{\dagger}\end{array}$ & $\begin{array}{l}\text { Injectable } \\
\text { method, \% }\end{array}$ & $\begin{array}{l}\text { Oral con- } \\
\text { traception, \% }\end{array}$ & IUD, \% & $\begin{array}{l}\text { Female steri- } \\
\text { lisation, \% }\end{array}$ & $\begin{array}{l}\text { Male sterili- } \\
\text { sation, \% }\end{array}$ & $\begin{array}{l}\text { Emer- } \\
\text { gency, \% }\end{array}$ & $\begin{array}{l}\text { Others, } \\
\%\end{array}$ & $\begin{array}{l}\text { Not } \\
\text { using, \% }\end{array}$ \\
\hline Total $(n=6296)$ & 49.1 & 41.8 & 25.0 & 8.6 & 1.6 & 8.1 & 2.3 & 0.9 & 11.4 & 50.9 \\
\hline Age (years) & & & $* * *$ & & & $* * *$ & $* *$ & & & \\
\hline $15-19(n=490)$ & 43.7 & 34.1 & 26.1 & 5.0 & 0.4 & 3.6 & 2.2 & 0.6 & 12.5 & 56.3 \\
\hline $20-34(n=3362)$ & 50.3 & 42.7 & 30.5 & 9.3 & 1.5 & 3.5 & 1.1 & 1.0 & 11.7 & 49.7 \\
\hline $35-49(n=2444)$ & 48.3 & 41.8 & 16.2 & 8.4 & 1.9 & 16.4 & 4.3 & 0.6 & 10.7 & 51.7 \\
\hline Race & $* * *$ & & $* * *$ & $* * *$ & $* * *$ & $* * *$ & $* * *$ & & * & $* * *$ \\
\hline Black African ( $n=3$ 982) & 47.2 & 39.7 & 27.5 & 6.8 & 1.1 & 6.3 & 1.3 & 0.9 & 11.8 & 52.8 \\
\hline White $(n=512)$ & 61.9 & 51.3 & 4.8 & 22.8 & 6.0 & 16.6 & 13.0 & 1.4 & 14.8 & 38.1 \\
\hline Coloured $(n=1$ 122) & 52.4 & 47.6 & 23.8 & 9.7 & 1.9 & 12.3 & 2.8 & 0.2 & 7.0 & 47.6 \\
\hline Indian/Asian $(n=670)$ & 61.1 & 58.3 & 6.8 & 22.5 & 3.8 & 27.9 & 1.4 & 0.2 & 5.3 & 38.9 \\
\hline Province & & & $* * *$ & $* *$ & & $* * *$ & $* *$ & * & $* * *$ & \\
\hline Western Cape $(n=820)$ & 54.0 & 49.3 & 23.8 & 7.2 & 2.6 & 15.6 & 5.5 & 0.1 & 8.5 & 46.0 \\
\hline Eastern Cape $(n=725)$ & 50.7 & 43.4 & 34.6 & 3.4 & 0.9 & 5.7 & 0.6 & 0.8 & 10.1 & 49.3 \\
\hline Northern Cape $(n=480)$ & 42.2 & 39.5 & 24.8 & 7.1 & 1.7 & 6.0 & 2.7 & 0.0 & 4.3 & 57.8 \\
\hline Free State $(n=459)$ & 52.6 & 44.2 & 29.7 & 12.0 & 3.1 & 7.0 & 1.5 & 3.2 & 15.8 & 47.4 \\
\hline KwaZulu-Natal $(n=1499)$ & 50.1 & 45.8 & 32.5 & 7.2 & 1.4 & 5.8 & 1.1 & 0.5 & 6.2 & 49.9 \\
\hline North West $(n=460)$ & 46.3 & 35.1 & 21.2 & 7.7 & 1.1 & 6.7 & 0.8 & 0.5 & 14.4 & 53.7 \\
\hline Gauteng $(n=876)$ & 48.1 & 39.0 & 18.4 & 11.1 & 1.7 & 9.7 & 3.3 & 0.9 & 13.1 & 51.9 \\
\hline Mpumalanga $(n=470)$ & 45.0 & 38.8 & 21.2 & 11.8 & 0.7 & 6.2 & 3.4 & 1.7 & 13.3 & 55.0 \\
\hline Limpopo $(n=507)$ & 46.3 & 34.9 & 21.3 & 9.1 & 1.1 & 5.9 & 0.6 & 0.7 & 18.4 & 53.7 \\
\hline Education status & & & $* * *$ & $* * *$ & * & & & * & & \\
\hline Grade 0 - $3(n=112)$ & 37.3 & 33.2 & 23.8 & 4.8 & 2.2 & 6.4 & 0.0 & 0.3 & 8.5 & 62.7 \\
\hline Grade 4 - $7(n=576)$ & 44.0 & 37.6 & 28.6 & 3.6 & 0.4 & 7.1 & 0.8 & 0.9 & 8.8 & 56.0 \\
\hline Grade 8 - $11(n=2$ 207) & 51.0 & 44.8 & 30.2 & 6.8 & 1.4 & 8.4 & 1.7 & 0.8 & 11.3 & 49.0 \\
\hline Grade $12(n=2149)$ & 49.8 & 41.2 & 24.1 & 10.5 & 1.3 & 7.1 & 2.0 & 0.5 & 12.5 & 50.2 \\
\hline Tertiary $(n=611)$ & 53.3 & 43.2 & 14.9 & 14.5 & 3.4 & 11.2 & 4.2 & 2.4 & 12.8 & 46.7 \\
\hline Socioeconomic status & & & $* * *$ & $* * *$ & $* *$ & $* * *$ & $* * *$ & & & \\
\hline Quartile $1(n=1204)$ & 48.2 & 41.7 & 33.2 & 5.7 & 1.0 & 4.4 & 0.2 & 0.6 & 10.5 & 51.8 \\
\hline Quartile $2(n=1300)$ & 48.3 & 40.5 & 30.4 & 5.6 & 1.1 & 5.2 & 0.8 & 0.5 & 11.7 & 51.7 \\
\hline Quartile 3 ( $n=1953$ ) & 47.5 & 40.0 & 23.1 & 9.6 & 1.2 & 8.7 & 2.3 & 1.0 & 12.3 & 52.5 \\
\hline Quartile 4 ( $n=1763)$ & 53.7 & 46.0 & 12.9 & 13.9 & 3.4 & 15.7 & 6.1 & 1.3 & 10.8 & 46.3 \\
\hline Ever pregnant $(n=5049)$ & $52.1^{\star * *}$ & 45.3 & $26.8^{* * *}$ & 8.9 & 1.5 & $9.5^{\star * *}$ & 2.4 & 0.7 & 11.0 & $47.9^{* * *}$ \\
\hline
\end{tabular}

women $(27.9 \%)$ was considerably more frequent than in other races, while $16.6 \%$ of white women had been sterilised, as had $13.0 \%$ of their male partners.

Compared with the poorest quartile, women in the two highest socioeconomic quartiles were much less likely to use injectable hormonal contraceptives (for QIII: odds ratio (OR) 0.60, 95\% confidence interval (CI) 0.46 - 0.78; and for QIV: OR 0.30, 95\% CI 0.22 - 0.41). However, the opposite associations were observed with all other contraceptive methods, higher socioeconomic quartiles being associated with increased odds of contraceptive use. Associations between educational level and contraceptive method mirrored those of socioeconomic status (SES). For example, the method mix for women with tertiary education differed considerably from others: $14.5 \%$ were using oral contraception and $2.4 \%$ had used emergency contraception - much higher than in other groups.

\section{Women's sexual behaviour and HIV risk by type of contraception}

Table 4 shows the distribution of sexual behaviour by contraceptive method. Overall, of all sexually active women, most reported $\leq 3$ lifetime sexual partners (75.0\%), and only $5.3 \%$ had had $>1$ partner over the past year. Close to $40.0 \%$ of participants mentioned having had age-disparate sex partners (partners $\geq 5$ years older than the woman). About a third used a condom at last sex (38.5\%) and reported consistent condom 
Table 4. Sexual behaviour and HIV status by current contraceptive use among sexually active women in SA, 2012

\begin{tabular}{|c|c|c|c|c|c|c|c|c|c|}
\hline $\begin{array}{l}\text { Variable } \\
\text { (unweighted } n \text { ) }\end{array}$ & $\begin{array}{l}\text { Total } \\
\text { popula- } \\
\text { tion, \% }\end{array}$ & $\begin{array}{l}\text { Injectable } \\
\text { method, } \\
\%\end{array}$ & $\begin{array}{l}\text { Oral } \\
\text { contra- } \\
\text { ception, \% }\end{array}$ & IUD, \% & $\begin{array}{l}\text { Female } \\
\text { sterili- } \\
\text { sation, \% }\end{array}$ & $\begin{array}{l}\text { Male } \\
\text { sterili- } \\
\text { sation, \% }\end{array}$ & $\begin{array}{l}\text { Emergency, } \\
\%\end{array}$ & $\begin{array}{l}\text { Others, } \\
\%\end{array}$ & $\begin{array}{l}\text { Not } \\
\text { using, } \\
\%\end{array}$ \\
\hline Lifetime sexual partners, $n$ & & & & & & & $* *$ & ** & \\
\hline $1(n=2162)$ & 31.9 & 31.5 & 35.2 & 33.3 & 38.3 & 34.9 & 26.3 & 23.9 & 30.9 \\
\hline $2-3(n=2495)$ & 43.1 & 45.0 & 36.5 & 29.1 & 40.5 & 38.5 & 28.1 & 43.8 & 43.1 \\
\hline $4-6(n=2495)$ & 20.3 & 20.1 & 23.2 & 27.1 & 17.9 & 26.0 & 45.1 & 23.5 & 21.0 \\
\hline$\geq 7(n=279)$ & 4.6 & 3.3 & 5.1 & 10.6 & 3.3 & 0.6 & 0.4 & 8.9 & 4.9 \\
\hline Partners in past year, $n$ & & & & & & & & $* *$ & * \\
\hline $1(n=5961)$ & 94.7 & 95.3 & 96.4 & 97.3 & 95.9 & 94.9 & 92.5 & 91.7 & 93.9 \\
\hline$\geq 2(n=298)$ & 5.3 & 4.7 & 3.6 & 2.7 & 4.1 & 5.1 & 7.5 & 8.3 & 6.1 \\
\hline \multicolumn{10}{|l|}{ Concurrent partners $^{\dagger}$} \\
\hline No $(n=80)$ & 56.1 & 58.2 & 82.4 & 39.7 & 48.6 & 0.0 & 51.4 & 59.7 & 56.0 \\
\hline Yes $(n=75)$ & 43.9 & 41.8 & 17.6 & 60.3 & 51.4 & 100 & 48.6 & 40.3 & 44.0 \\
\hline Intergenerational sex & & & & & $* *$ & * & & * & \\
\hline No $(n=3885)$ & 60.4 & 59.9 & 64.0 & 69.8 & 49.0 & 42.8 & 56.7 & 66.1 & 60.4 \\
\hline Yes $(n=2321)$ & 39.6 & 40.1 & 36.0 & 30.2 & 51.0 & 57.2 & 43.3 & 33.9 & 39.6 \\
\hline \multicolumn{10}{|l|}{ Condom use at last sex } \\
\hline No $(n=4066)$ & 61.5 & 63.8 & 67.5 & 70.9 & 76.7 & 81.3 & 47.3 & 34.4 & 60.1 \\
\hline Yes $(n=2094)$ & 38.5 & 36.2 & 32.5 & 29.1 & 23.3 & 18.7 & 52.7 & 65.6 & 39.9 \\
\hline Consistency of condom use & & & $* * *$ & & $* *$ & & & $* * *$ & * \\
\hline $\begin{array}{l}\text { Inconsistent or none } \\
(n=4519)\end{array}$ & 69.6 & 72.5 & 80.2 & 76.3 & 80.8 & 77.0 & 52.8 & 50.5 & 67.3 \\
\hline Yes $(n=1687)$ & 30.4 & 27.5 & 19.8 & 23.7 & 19.2 & 23.0 & 47.2 & 49.5 & 32.7 \\
\hline $\begin{array}{l}\text { Perceived risk of HIV } \\
\text { infection }\end{array}$ & & $* * *$ & $* *$ & & $* * *$ & $* *$ & & * & \\
\hline Low risk $(n=4425)$ & 65.4 & 57.2 & 74.1 & 71.4 & 79.8 & 87.7 & 56.9 & 59.4 & 66.5 \\
\hline High risk $(n=1820)$ & 34.6 & 42.8 & 25.9 & 28.6 & 20.2 & 12.3 & 43.1 & 40.6 & 33.5 \\
\hline HIV status & & & * & $* *$ & $* *$ & & & & \\
\hline Negative ( $n=3968$ ) & 73.3 & 72.2 & 80.6 & 89.6 & 83.3 & 82.6 & 78.1 & 71.1 & 71.6 \\
\hline Positive ( $n=1083$ ) & 26.7 & 27.8 & 19.4 & 10.4 & 16.7 & 17.4 & 21.9 & 28.9 & 28.4 \\
\hline
\end{tabular}

use (30.4\%). Sexual behaviours among women using injectables were broadly similar to those of other women. For oral contraceptive users, however, $11.0 \%$ of whites reported consistent condom use compared with $25.1 \%$ of black Africans. These patterns were similar in women who had been sterilised (11.7\% of white women reporting consistent condom use compared with $26.7 \%$ of black African women). Those not using any method of contraception were more likely to have multiple sexual partners in the past year (6.1\%) than other women, but otherwise had similar behaviours as contraceptive users. Younger women (aged 15 - 19 years) who used modern contraception were less likely to report multiple sexual partners in the past year than non-users $(4.2 \%$ among users v. $8.0 \%$ among non-users, $p=0.002$ ). However, those using contraception had lower levels of consistent condom use than other youth $(23.6 \%$ v. $38.9 \%, p<0.001)$.

One-third of sexually active women perceived themselves to be at high risk of HIV infection (34.6\%). Perceptions of risk for HIV varied by race and contraceptive method. Perceptions of high risk were markedly higher among black Africans than other race groups. Some $46.2 \%$ of black African women currently using injectables felt they were at high risk for HIV infection, higher than levels among black Africans using oral contraceptives (38.6\%) and sterilisation (30.7\%), or those not using any methods (38.3\%). Less than $5 \%$ of white, coloured or Indian/Asian women perceived themselves at risk for HIV, with similar levels between women using different contraceptive methods. Interestingly, perceptions of HIV risk were high among women who used emergency contraception (43.1\%), but they also reported high levels of consistent condom use (47.2\%). HIV-positive women were less likely than HIV-negative women to use oral contraception, IUDs or to have been sterilised. Use of injectables did not vary by HIV status.

\section{Discussion}

In this national survey of women, about $41.0 \%$ were using modern contraception. Gradual increments have been made in contraception prevalence over time in SA, although the rate of increase appears 
to be slowing. Consistent with rises in contraception use, the total fertility rate has declined gradually, from 2.7 children per woman in 2002 to 2.3 in 2013. ${ }^{[25]}$ The fastest rate of change in fertility occurred in the Eastern Cape and KwaZulu-Natal, provinces with among the highest levels of contraceptive prevalence in this study. Of note, we found that about two-thirds of all pregnancies were unintended, similar to levels reported in several smaller studies. ${ }^{[26-28]}$ The rate of unintended pregnancy was even higher in young women, who commonly experience stigma and economic difficulties during pregnancy, ${ }^{[29]}$ and especially high levels of maternal morbidity and mortality. ${ }^{[30-32]}$

Low levels of knowledge and frequent misconceptions about contraception among women of $15-19$ years are particularly concerning. ${ }^{[3,34]}$ These findings cast doubt on how effectively the national Integrated School Health Policy ${ }^{[35,36]}$ is being implemented. The policy recommends that school health services act as a delivery platform for the provision of sexual and reproductive health services, such as contraception and condom distribution. ${ }^{[37]}$ Legally, anyone aged $\geq 12$ years has the right to receive contraception without parental consent. ${ }^{[38]}$ The provision of contraception in schools, however, requires the explicit permission of individual school-governing bodies - few have, however, given permission. ${ }^{[39]}$ When contraception services are made available, school-based services will need to be carefully designed to counter adolescents' concerns around privacy, ${ }^{[35]}$ as also noted in studies of HIV testing in schools. ${ }^{[40]}$ Youth-friendly services in community-based primary care facilities are another important option for improving adolescent access to contraception. Over the past two decades, many initiatives have been made in this direction in SA. ${ }^{[36,41]}$ These programmes reached high coverage and performed well against predefined standards relating to services provided and clinical environment. ${ }^{[2,43]}$ In recent years, however, several reports have noted weaknesses in these programmes and the need for strengthening of these services. ${ }^{[36,43,44]}$

In the public sector, more broadly, supply-side barriers include strong provider preferences for particular methods, lengthy waits at clinic services, and staff with negative attitudes, e.g. towards young women requesting contraception or an abortion. ${ }^{[45]}$ Although, overall, women largely make use of the public sector for healthcare, ${ }^{[46]}$ a large proportion of women in our study turned to private sector doctors or pharmacists, where they are offered a wider mix of methods. This suggests that the government's policy, that women requesting contraception should receive the method of their choice, has not been fully actualised, especially in primary health clinics and community centres. Contraception use and method type are strongly associated with race in this study and also with SES at an individual and geographical level. Marked differentials between poor and wealthy districts were noted in other studies. ${ }^{[47-49]}$ All the abovementioned reasons relating to age and SES mean that younger poorer women are particularly vulnerable to unintended pregnancies, and much remains to be done to mitigate their risk. ${ }^{[33,49,50]}$

The National Contraception and Fertility Planning Policy and Service Delivery Guidelines ${ }^{[51]}$ in 2012 marked an important step away from methods requiring users' adherence, and placed particular emphasis on LARC methods, aiming to raise choice and contraceptive effectiveness (a quarter of women who had a pregnancy reported contraceptive failure in our study). The guidelines state that clients should have access to accurate, unbiased information about all available methods to make an informed choice'. In practice, what is available in primary level facilities varies and coverage of services for sterilisation, and even IUD insertion, is extremely limited in some districts. ${ }^{\left[{ }^{[6]}\right.}$ Facilities such as those for HIV treatment seldom offer contraceptive services. Ensuring adequate stocks of the wide range of contraceptive methods is contingent on accurate forecasting of the demand for each method. This is difficult to achieve, given the limited data available in the public sector to predict the anticipated demand, especially for new methods. ${ }^{[36]}$

With injectable contraception, which comprises three-quarters of the modern methods used, method discontinuation, timeliness of repeat injections, and switching remain key contributors to contraception failures in SA. ${ }^{[17,18,21]}$ Up to half of women in a study in the Eastern and Western Cape were late for their re-injection appointment. ${ }^{[18]}$ Women, however, have limited knowledge of and experience with the 'newer' contraceptive methods. ${ }^{[26,33,34,52,53]}$ Only half of our participants had heard of emergency contraception, the same portion as a study among female university students in $2011,{ }^{[54]}$ but higher than the $30.0 \%$ knowledge found in a Cape Town study of women in public sector clinics in 2004/2005. ${ }^{[53]}$ Clearly, the introduction of LARCs and future multipurpose technologies will require intensive awareness campaigns, encompassing efforts to address health worker misperceptions of these technologies. ${ }^{[10,11]}$ Encouragingly, despite these problems, uptake of sub-dermal implants, rolled out in 2014 in SA and accompanied by substantial promotion efforts, has been encouraging. ${ }^{[55]}$ Training manuals covering implant insertion were developed and $>6000$ providers were trained, mainly nurses. While as many as 800000 devices had been inserted by the end of 2014, ${ }^{[56]}$ the delivery of the method has been hampered by poor data for monitoring adverse effects, such as early removal of the device, and poor communication by the National Department of Health around concerns of drug interactions between the antiretroviral drug efavirenz and the synthetic progesterones in the implant. ${ }^{[36]}$

Injectable contraception, particularly DMPA, has been associated with an increased risk of HIV acquisition in some, but not all, studies. ${ }^{[57,58]}$ Overall, systematic reviews and an individual patient data meta-analysis suggest about a 1.5-fold increased risk of HIV acquisition with DMPA exposure, ${ }^{[59,60]}$ but many studies included in these reviews have important methodological flaws. ${ }^{[61]}$ After many years of calls for a randomised controlled trial to deeply examine this relationship, a trial will commence shortly. ${ }^{[62,63]}$ Until further data are available, it is likely that the benefits of discouraging DMPA use would be outweighed by the risks of unwanted pregnancy and maternal deaths. This is especially true of countries such as Madagascar, with high maternal mortality risks, ${ }^{[64]}$ but perhaps less so in SA.

In our study, HIV-positive women were less likely than HIVnegative women to use oral contraception and IUDs. Some evidence indicates that many health workers hold misconceptions about interactions between contraception and antiretroviral treatment, and offer HIV-positive women different contraceptives than other women. ${ }^{[10,26,65-68]}$ Other studies, however, have found that HIVpositive and HIV-negative women have a similar methods mix and fertility goals. ${ }^{[26,65,68-70]}$ Integration of family planning within services for antiretroviral treatment and for prevention of motherto-child transmission holds much promise in raising contraceptive prevalence among HIV-positive women, ${ }^{[1,27,71]}$ although it is not without challenges. ${ }^{[72]}$

\section{Study limitations}

This article provides population-level representative data for the country, a uniquely important dataset. However, cross-sectional studies such as this one do not allow for observation of temporal relationships. This study cannot ascertain which contraceptive method was used at the time of HIV acquisition and thus cannot investigate causal associations between HIV infection and contraception method, for example. Additional limitations include a reliance on self-reporting of contraceptive use. It was therefore not possible to assess methods 
dispensed, but not actually used, or used incorrectly (especially user-dependent methods such as oral contraception and condoms)..$^{[73]}$ Finally, while the study provides some measure of unmet need for contraception, this indicator is hard to measure, and the variable used (unintended pregnancy) only provides limited information. ${ }^{[74,75]}$

\section{Conclusion}

Even though levels appear to be rising slowly over time, less than half of SA women were using a modern contraceptive method in 2012. Women with only primary school education and of lower SES were less likely to report contraceptive use. In light of high unintended pregnancy rates and contraceptive failure noted in this study, it is hoped that SA's new contraceptive policy and clinical guidelines ${ }^{[5,76]}$ will be fully implemented as a national health priority. Additional emphasis on access to LARCs, particularly among women in poorer provinces and with lower SES, is necessary in the coming years to further improve the SA family planning services. Until then, injectable contraception remains an important contraceptive method for women in this country, particularly for black African women and those with lower SES, who do not yet have access to a range of methods. In common with other countries, ${ }^{[77]}$ young women had low contraception use and poorer levels of knowledge about these methods, making it clear that the reproductive health component of the School Health Programme needs to be considerably strengthened. It is very disappointing that many young women leave school with little knowledge of contraception. In summary, access to contraception and choice of a range of methods are key interventions to improve population health, particularly that of women. Increased political and economic investment is necessary to decrease disparities in access to contraception between population groups and to raise overall levels of contraception.

1. Feucht UD, Meyer A, Kruger M. Missing HIV prevention opportunities in South African children - a 7-year review. BMC Public Health 2014;14(1):1265-1273. https://doi.org/10.1186/1471-2458-14-1265

2. Michalow J, Chola L, McGee S, et al. Triple return on investment: The cost and impact of 13 interventions that could prevent stillbirths and save the lives of mothers and babies in South Africa. BMC Preg Child 2015;15(1):456. https://doi.org/10.1186/s12884-015-0456-9

3. Cleland J, Harbison S, Shah IH. Unmet need for contraception: Issues and challenges. Stud Fam Plann 2014;45(2):105-122. https://doi.org/10.1111/j.1728-4465.2014.00380.x

4. Darroch JE, Singh S. Trends in contraceptive need and use in developing countries in 2003, 2008, and 2012: An analysis of national surveys. Lancet 2013;381(9879):1756-1762. https://doi.org/10.1016/s01402012: An analysis

5. United Nations (UN) Department of Economic and Social Affairs Population Division. Model-based United Nations (UN) Department of Economic and Social Affairs Population Division. Model-based
estimates and projections of family planning indicators, 2013 revision. http://un.org/en/development/ estimates and projections of family planning indicators, 2013 revision. http://un.org/en/
desa/population/theme/family-planning/cp_model.shtml (accessed 12 December 2016).

6. Massyn N, Day C, Peer N, et al. District Health Barometer 2013/14. Durban: Health Systems Trust, Massyn N, Day C, Peer N, et al. District Health Barometer 2013/14. Durban: Health Systems Trust,
2014. https://health-e.org.za/wp-content/uploads/2014/10/DHB_2013-14.pdf (accessed 14 December 2016)

7. National Department of Health. South Africa Demographic and Health Survey. Pretoria: NDoH, 2003 . Alkema L, Kantorova V, Menozzi C, Biddlecom A. National, regional, and global rates and trends in contraceptive prevalence and unmet need for family planning between 1990 and 2015: A systematic and comprehensive analysis. Lancet 2013;381(9878):1642-1652. https://doi.org/10.1016/S0140-6736(12)62204-1

9. Blanchard K, Chipato T, Ramjee G, Nhemachena T, Harper CC. Clinicians' perceptions and provision of hormonal contraceptives for HIV-positive and at-risk women in Southern Africa: An original research article. Contraception 2014;90(4):391-398. https://doi.org/10.1016/j.contraception.2014.04.010

10. Morse J, Chipato T, Blanchard K, et al. Provision of long-acting reversible contraception in HIVprevalent countries: Results from nationally representative surveys in southern Africa. Br J Obstet
Gynaec 2013;120(11):1386-1394. https://doi.org/10.1111/1471-0528.12290

11. Gutin SA, Mlobeli R, Moss M, Buga G, Morroni C. Survey of knowledge, attitudes and practices sutrounding the intrauterine device in South Africa. Contraception 2011;83(2):145-150. https://doi.
surroces org/10.1016/j.contraception.2010.07.009

12. Ross JA, Agwanda AT. Increased use of injectable contraception in sub-Saharan Africa. Afr J Reprod Health 2012;16(4):68-80.

3. Volscho T. Racism and disparities in women's use of the Depo-Provera injection in the contemporary USA. Crit Sociol 2011;37(5):673-688. https://doi.org/10.1177/0896920510380948

14. Metoyer AB. Racial and socioeconomic disparities in use of long-lasting contraception. In: Ronenfeld JJ, ed. Social Sources of Disparities in Health and Health Care and Linkages to Policy, Population Concerns and Providers of Care (Research in the Sociology of Health Care, Volume 27). Bradford, UK: Emerald Group Publishing, 2009:109-134.

15. Smith A. Not an Indian tradition: The sexual colonization of native peoples. Hypatia 2003;18(2):70-85. https://doi.org/10.1353/hyp.2003.0042

16. Tait CA. A study of the service needs of pregnant addicted women in Manitoba. Winnipeg: Prairie Women's Health Centre of Excellence, 2000. http://gov.mb.ca/health/documents/PWHCE_June2000.pdf (accessed 12 December 2016)

17. Smit JA, Beksinska ME. Hormonal contraceptive continuation and switching in South Africa: Implications for evaluating the association of injectable hormonal contraceptive use and HIV. J Acquir Immune Defic Syndr 2013;62(3):363-365. https://doi.org/10.1097/QAI.0b013e31827e818a
18. Baumgartner JN, Morroni C, Mlobeli RD, et al. Timeliness of contraceptive reinjections in South Africa and its relation to unintentional discontinuation. Int Fam Plan Perspect 2007;33(2):66-74. https://doi org/10.1363/ifpp.33.066.07

19. Shisana O, Rehle T, Simbayi L, et al. South African National HIV Prevalence, Incidence and Behaviour Survey, 2012. Cape Town: HSRC Press, 2014

20. World Health Organization. Reproductive Health Indicators: Guidelines for Their Generation, Interpretation and Analysis for Global Monitoring. 2006. http://who.int/reproductive-health/publications/rh_indicators/ index.html (accessed 15 September 2016).

21. Beksinska ME, Smit JA, Mantell JE. Progress and challenges to male and female condom use in South Africa. Sex Health 2012;9(1):51-58. https://doi.org/10.1071/SH11011

22. Wabiri N, Chersich M, Zuma K, Blaauw D, Goudge J, Dwane N. Equity in maternal health in South Africa: Analysis of health service access and health status in a national household survey. PLoS ONE 2013;8(9):e73864. https://doi.org/10.1371/journal.pone.0073864

23. Wabiri N, Chersich M, Shisana O, Blaauw D, Rees H, Dwane N. Growing inequities in maternal health in South Africa: A comparison of serial national household surveys. BMC Preg Child 2016;16(1):256. https://doi.org/10.1186/s12884-016-1048-z

24. Shisana O, Rehle T, Simbayi L, et al. South African National HIV Prevalence, Incidence and Behaviour Survey, 2012. Cape Town: HSRC Press, 2014.
Shisana Oen

25. Statistics South Africa. Mid-year Population Estimates. Pretoria: SSA, 2013

26. Crede S, Hoke T, Constant D, Green MS, Moodley J, Harries J. Factors impacting knowledge and use of long acting and permanent contraceptive methods by postpartum HIV positive and negative women in Cape Town, South Africa: A cross-sectional study. BMC Public Health 2012,12(1):197-206. https://doi org/10.1186/1471-2458-12-197

27. Schwartz SR, Rees H, Mehta S, Venter WD, Taha TE, Black V. High incidence of unplanned pregnancy after antiretroviral therapy initiation: Findings from a prospective cohort study in South Africa. PLoS ONE 2012;7(4):e36039. https://doi.org/10.1371/journal.pone.0036039

28. Matthews LT, Crankshaw T, Giddy J, et al. Reproductive decision-making and periconception practices among HIV-positive men and women attending HIV services in Durban, South Africa. AIDS Behav 2013;17(2):461-470. https://doi.org/10.1007/s10461-011-0068-y

29. Scorgie F, Blaauw D, Dooms T, Coovadia A, Black V, Chersich M. 'I get hungry all the time': Experiences of poverty and pregnancy in an urban healthcare setting in South Africa. Glob Health 2015;11(1):37-49. https://doi.org/10.1186/s12992-015-0122-z

30. National Committee for Confidential Enquiry into Maternal Deaths. Saving Mothers 2008 - 2010: Fifth . National Committee for Confidential Enquiry into Maternal Deaths. Saving Mothers 2008 - 2010: Fifth
Report on the Confidential Enquiries into Maternal Deaths in South Africa Saving Mothers 2008 - 2010. Report on the Confidential Enquiries in
Pretoria: Department of Health, 2010.

31. Mkhwanazi N. Understanding teenage pregnancy in a post-apartheid South African township. Cult Health Sex 2010;12(4):347-358. https://doi.org/10.1080/13691050903491779

32. McHunu G, Peltzer K, Tutshana B, Seutlwadi L. Adolescent pregnancy and associated factors in South African youth. Afr Health Sci 2012;12(4):426-434. https://doi.org/10.4314/ahs.v12i4.5

33. Ramathuba DU, Khoza LB, Netshikweta ML. Knowledge, attitudes and practice of secondary schoo girls towards contraception in Limpopo Province. Curationis 2012;35(1):E1-E7. https://doi.org/10.4102/ curationis.v35i1.45

34. Lebese RT Maputle SM, Ramathuba DU, Khoza LB. Factors influencing the uptake of contraception services by Vatsonga adolescents in rural communities of Vhembe District in Limpopo Province, South Africa. Health SA Gesondheid 2013;18(1):6. https://doi.org/10.4102/hsag.v1811.654

35. National Department of Health, Department of Basic Education. Integrated School Health Policy. Pretoria: NDoH, 2012.

36. Lince-Deroche N, Pleaner M, Harries J, et al. National health review: Achieving universal access to sexual and reproductive health services: The potential and pitfalls for contraceptive services in South Africa. 2016. and reproductive health services: The potential and pitfalls for contraceptive services in South $A$.
http://hst.org.za/publications/south-african-health-review-2016 (accessed 24 February 2017).

37. Shung-King M. From 'stepchild of primary healthcare' to priority programme: Lessons for the implementation of the National Integrated School Health Policy in South Africa. S Afr Med J 2013;103(12):895-898. https:/ doi.org/10.7196/samj.7550

38. South Africa. Children’s Act, 2005 (Act No. 38 of 2005). Government Gazette No. 28944:492. 2005.

39. Shung-Kingi M, Orgill M, Slemming W. National health review: School health in South Africa: Reflections on the past and prospects for the future. 2013/14. http://hst.org.za/publications/southafrican-health-review-201314 (accessed 24 February 2017).

40. Strauss M, George GL, Rhodes BD. Determining preferences related to HIV counselling and testing services among high school learners in KwaZulu-Natal: A discrete choice experiment. AIDS Behav 2016. https://doi.org/10.1007/s10461-016-1602-8

41. Dickson-Tetteh K, Pettifor A, Moleko W. Working with public sector clinics to provide adolescentfriendly services in South Africa. Reprod Health Matters 2001;9(17):160-169. https://doi.org/10.1016/ s0968-8080(01)90020-5

42. Hainsworth G, Engel DM, Simon C, Rahimtoola M, Ghiron LJ. Scale-up of adolescent contraceptive services: Lessons from a 5-country comparative analysis. J Acquir Immune Defic Syndr 2014;66(Suppl 2):S200-S208. https://doi.org/10.1097/QAI.0000000000000180

43. Geary RS, Webb EL, Clarke L, Norris SA. Evaluating youth-friendly health services: Young people's perspectives from a simulated client study in urban South Africa. Glob Health Action 2015;8(1):2608026088. https://doi.org/10.3402/gha.v8.26080

4. Geary RS, Gomez-Olive FX, Kahn K, Tollman S, Norris SA. Barriers to and facilitators of the provision of a youth-friendly health services programme in rural South Africa. BMC Health Serv Res 2014;14(1):259-268. https://doi.org/10.1186/1472-6963-14-259

45. Holt K, Lince N, Hargey A, et al. Assessment of service availability and health care workers' opinion about young women's sexual and reproductive health in Soweto, South Africa. Afr J Reprod Health 2012;16(2):283-293.

46. Shisana O, Labadarios D, Rehle T, et al. South African National Health and Nutrition Examination Survey (SANHANES-1). Cape Town: HSRC Press, 2013.

47. Massyn N, Day C, Peer N, Padarath A, Barron P, English R. District Health Barometer 2013/14. Durban: Health Systems Trust, 2014.

48. Adebowale SA, Adedini SA, Ibisomi LD, Palamuleni ME. Differential effect of wealth quintile on modern contraceptive use and fertility: Evidence from Malawian women. BMC Women's Health 2014;14(1):40. https://doi.org/10.1186/1472-6874-14-40

9. Stephenson R, Beke A, Tshibangu D. Community and health facility influences on contraceptive method choice in the Eastern Cape, South Africa. Int Fam Plan Perspect 2008;34(2):62-70. https://doi. org/10.1363/ifpp.34.062.08

50. MacPhail C, Pettifor AE, Pascoe S, Rees HV. Contraception use and pregnancy among 15 - 24 year old South African women: A nationally representative cross-sectional survey. BMC Med 2007;5(1):31-39. https://doi.org/10.1186/1741-7015-5-31

51. National Department of Health. National Contraception and Fertility Planning Policy and Service Delivery Guidelines. Pretoria: NDoH, 2013.

52. Seutlwadi L PK, Mchunu G, Tutshana BO. Contraceptive use and associated factors among South African youth (18 - 24 years): A population-based survey. S Afr J Obstet Gynaecol 2012;8(2):43-47.

53. Myer L, Mlobeli R, Cooper D, Smit J, Morroni C. Knowledge and use of emergency contraception among women in the Western Cape province of South Africa: A cross-sectional study. BMC Women's
among Health 2007;7(1):14-21. https://doi.org/10.1186/1472-6874-7-14 
54. Hoque ME, Ghuman S. Knowledge, practices, and attitudes of emergency contraception among female university students in KwaZulu-Natal, South Africa. PLoS ONE 2012;7(9):e46346. https://doi. org/10.1371/journal.pone. 0046346

55. Parliamentary Monitoring Group. Minister of Health, Dr Aaron Motsoaledi, gave his budget vote speech on 23 July 2014. 2014. http://pmg.org.za/briefing/20140723-minister-health-budget-vote-speech (accessed 25 January 2017).

56. National Department of Health. National Perspective: Subdermal Implant Roll-out Statistics. The Contraceptive Implant in South Africa. Pretoria: NDoH, 2015.

57. Morrison CS, Turner AN, Jones LB. Highly effective contraception and acquisition of HIV and other . org/10.1016/j.bpobgyn.2008.11.004

58. Morrison CS, Nanda K. Hormonal contraception and HIV. An unanswered question. Lancet Infect Dis 2012;12(1):2-3. https://doi.org/10.1016/S1473-3099(11)70254-7

59. Morrison CS, Chen PL, Kwok C, et al. Hormonal contraception and the risk of HIV acquisition: An individual participant data meta-analysis. PLoS Med 2015;12(1):e1001778. https://doi.org/10.1371/ journal.pmed.1001778

60. Ralph LJ, McCoy SI, Shiu K, Padian NS. Hormonal contraceptive use and women's risk of HIV acquisition: A meta-analysis of observational studies. Lancet Infect Dis 2015;15(2):181-189. https://doi. org/10.1016/S1473-3099(14)71052-7

61. Hofmeyr GJ, Singata M, Sneden J. Hormonal contraception for women exposed to HIV infection Cochrane Database Syst Rev 2014;(5):CD009741. https//doi. org/10.1002/14651858.CD009741 pub2 2. Colvin CI, Harrison A. Broadening the debate over HIV and hormonal contraception. Lancet Infect Di 2015;15(2):135-136. https://doi.org/10.1016/s1473-3099(14)71076-x

63. Rees H, for The ECHO Consortium. DMPA and HIV: Why we need a trial. Contraception 2014;90(4):354 356. https://doi.org/10.1016/i.contraception.2014.08.007

64. Jain AK. Hormonal contraception and HIV acquisition risk: Implications for individual users and public policies. Contraception 2012;86(6):645-652. https://doi.org/10.1016/j.contraception.2012.03.008

65. Laher F, Todd CS, Stibich MA, et al. A qualitative assessment of decisions affecting contraceptive utilization and fertility intentions among HIV-positive women in Soweto, South Africa. AIDS Behav 2009;13(Suppl 1):47-54. https://doi.org/10.1007/s10461-009-9544-2

66. Marlow HM, Maman S, Groves AK, Moodley D. Fertility intent and contraceptive decision-making among HIV positive and negative antenatal clinic attendees in Durban, South Africa. Health Care Women Int 2012;33(4):342-358. https://doi.org/10.1080/07399332.2012.655390
67. Holt K, Blanchard K, Chipato T, et al. A nationally representative survey of healthcare provider counselling and provision of the female condom in South Africa and Zimbabwe. BMJ Open 2013;3(3). counselling and provision of the female condo
https://doi.org/ $10.1136 /$ bmjopen-2012-002208

68. Cooper D, Moodley J, Zweigenthal V, Bekker LG, Shah I, Myer L. Fertility intentions and reproductive health care needs of people living with HIV in Cape Town, South Africa: Implications for integrating reproductive health and HIV care services. AIDS Behav 2009;13(Suppl 1):38-46. https://doi.org/10.1007/ s10461-009-9550-1

69. Myer L, Morroni C, Rebe K. Prevalence and determinants of fertility intentions of HIV-infected women and men receiving antiretroviral therap

70. Kaida A, Laher F, Strathdee SA, et al. Childbearing intentions of HIV-positive women of reproductive age in Soweto, South Africa: The influence of expanding access to HAART in an HIV hyperendemic setting. Am J Public Health 2011;101(2):350-358. https://doi.org/10.2105/AJPH.2009.177469

71. Kaida A, Laher F, Strathdee SA, et al. Contraceptive use and method preference among women in Soweto, South Africa: The influence of expanding access to HIV care and treatment services. PLoS ONE 2010;5(11):e13868. https://doi.org/10.1371/journal.pone.0013868

72. Smit JA, Church K, Milford C, Harrison AD, Beksinska ME. Key informant perspectives on policy- and care in South Africa. BMC Health Serv Res 2012;12(1):48-56. https:///doi.org/10.1186/1472-6963-12-48

73. Callahan R, Nanda K, Kapiga S, et al. Pregnancy and contraceptive use among women participating in the FEMPrEP trial. J Acquir Immune Defic Syndr 2015;68(2):196-203. https://doi.org/10.1097/qai.0000000000000413

74. Evens E, Tolley E, Headley J, et al. Identifying factors that influence pregnancy intentions: Evidence from South Africa and Malawi. Cult Health Sex 2015;17(3):374-389. https://doi.org/10.1080/1369105 8.2014.968806

75. Mantell JE, Exner TM, Cooper D, et al. Pregnancy intent among a sample of recently diagnosed HIVpositive women and men practicing unprotected sex in Cape Town, South Africa. J Acquir Immune Defic Syndr 2014;67(Suppl 4):S202-S209. https://doi.org/10.1097/qai.0000000000000369

76. National Department of Health. National Contraception Clinical Guidelines. Pretoria: NDoH, 2012.

77. McCurdy RJ, Schnatz PF, Weinbaum PJ, Zhu J. Contraceptive use in adolescents in sub-Saharan Africa: Evidence from demographic and health surveys. Conn Med 2014;78(5):261-272

Accepted 13 December 2016 